\title{
Trakcyjny napęd asynchroniczny o podwyższonej sprawności energetycznej z wykorzystaniem pojemnościowego zasobnika energii.
}

\begin{abstract}
Artykuł przedstawia analizę kryteriów oraz droge sformułowania założen projektowych, a także praktycznq realizację układu napędu trolejbusu. Przedstawiono dwa istotne zagadnienia, które maja decydujacy wplyw na podniesienie sprawności energetycznej, jakimi sa układ falownika, który umożliwia efektywne wykorzystanie zasobnika pojemnościowego złożonego z baterii superkondensatorów oraz sam dobór $i$ wymiarowanie zasobnika z uwzględnieniem aspektów ekonomicznych.
\end{abstract}

\begin{abstract}
1.Wstęp
Nowoczesne technologie stwarzają możliwość dalszego rozwoju już istniejących rozwiązań, jak i też poszukiwania nowych. Wcześniej, na rozwój napędów trakcyjnych miało lbrzymi wpływ opanowanie technologii półprzewodników mocy, tranzystory IGBT, tyrystory IGTC itp. oraz technologii układów mikroprocesorowych, które pozwoliły na podwyższenie parametrów technicznych pojazdów ,w tym jakże ważną sprawność energetyczną. Obok komfortu pasażerów i niezawodności, oszczędność energii staje się coraz istotniejszym kryterium wyboru i oceny napędu trakcyjnego. Nowa technologia kondensatorów o bardzo dużej gęstości absorbowanej energii w odniesieniu do masy i objętości otwiera drogę do dalszego obniżenia energii pobieranej przez napęd pojazdu trakcyjnego z podstacji. Poniżej przedstawiono strukturę napędu asynchronicznego $\mathrm{z}$ zasobnikiem pojemnościowym oraz propozycję kryteriów wymiarowania zasobnika.
\end{abstract}

\section{Struktura napędu}

Do analizy struktury napędu przyjęto, że zasobnik pojemnościowy będzie zabudowany na pojeździe [2]. Znana są aplikacje, w których zasobnik jest związany z siecią trakcyjną i podstacją [4], [5]. Za tym rozwiązaniem przemawia fakt, że zasobnik nie obciąża pojazdu i może wymieniać energię z różnymi pojazdami. Jednakże , zdaniem autora większe korzyści pojawiaja się, gdy każdy pojazd jest wyposażony indywidualny zasobnik. Wówczas układ sterowania precyzyjnie rozpoznaje stan pojazdu i pozwala na efektywne wykorzystanie zasobnika , nie ma konieczności analizowania stanu całego systemu zasilania [3], [6]. Ponadto pojawia się możliwość zasilania nawet przy braku napięcia $\mathrm{w}$ sieci - zjazd awaryjny $\mathrm{z}$ odcinka izolowanego [1]. Również, co jest bardzo istotne, można uniknąć wypływu energii do sieci. Wówczas są eliminowane są straty w sieci, a także wzrost napięcia , które jest nieunikniony przy przekazywaniu energii do innego pojazdu.

\subsection{Wybór struktury napędu}

Przy konstruowaniu struktury zostały uwzględnione dwa ważne kryteria odnoszące się do wymagań eksploatacyjnych, tj. wymagania normatywne oraz podatność na modyfikacje.

\section{Wymagania normatywne}

Jednym $\mathrm{z}$ istotnych wymagań stawianych napędom w pojazdach komunikacji miejskiej jest zapewnienie skutecznego hamowania elektrodynamicznego podczas wjazdu na odcinek sieci uziemionej lub pozbawionej zasilania.

\section{Podatność na modyfikacje}

Systemy komunikacji miejskiej poszczególnych aglomeracji, cechuje duże zróżnicowanie zarówno pod względem parametrów sieci zasilającej, jak i wymagań przewozowych. Struktura napędu zasobnikowego powinna pozwalać na łatwe dostosowanie do oczekiwań wymagań, nawet trakcie trwania okresu eksploatacji. Wymagany czas eksploatacji nowego taboru osiaga 20 lat i więcej, tak więc należy spodziewać się, że w tym czasie mogą się znacznie zmienić parametry infrastruktury zasilania oraz wymagania przewozowe.

\section{Schemat blokowy napędu}

W działaniu napędu z zasobnikiem, można wyróżnić szereg odmiennych faz pracy, w których zachodzi przetwarzanie energii elektrycznej na mechaniczną ( $\mathrm{E}$ $\rightarrow M)$ i odwrotnie $(E \leftarrow M)$. Na podstawie schematu $\mathrm{z}$ rysunku Rys.1. zostanie przedstawione zakładane działanie napędu wraz z poszczególnymi blokami. 


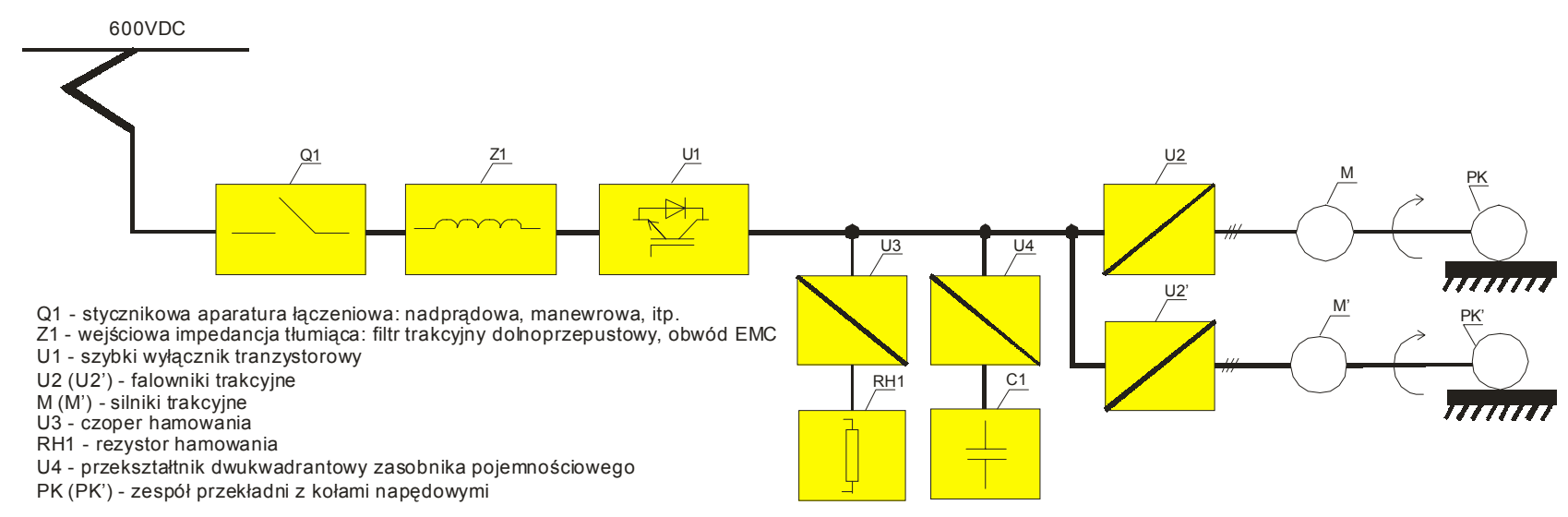

Rys.1: Schemat blokowy napędu asynchronicznego z zasobnikiem pojemnościowym.

Q1 - blok aparatury stykowej umożliwia odłaczenie napędu od sieci trakcyjnej, sprawność energetyczna wynosi ok. $100 \%$

Z1 - blok zapewnienia ograniczanych nie zaktóceń, zarówno doprowadzanych przez napęd do sieci, jak i odwrotnie, sprawność energetyczna ok. 100\%.

U1 - szybki pólprzewodnikowy odtacznik, umożliwiajacy praktycznie natychmiastowe przerwanie wyplywu prqdu znapędu do sieci trakcyjnej, sprawność energetyczna ok. 0,992.

U2 (U2') - trójfazowy falownik trakcyjny zapewniajacy sterowanie silnikami zarówno podczas jazdy, jak i hamowania oraz umożliwiajacy zmianę kierunku jazdy, sprawność energetyczna ok. 0,98.

$\boldsymbol{M}\left(M^{\prime}\right)$ - trójfazowy, asynchroniczny silnik trakcyjny, sprawność energetyczna ok. 0,94

PK - zespót przektadni z kołami napędowymi, sprawność energetyczna ok. 0,96.

U3, $\boldsymbol{R H 1}$ - czoper hamowania, rezystor umożliwiajacy rozproszenie energii na ciepło oddane do otoczenia.

U4 - przeksztaltnik dwukwadrantowy umożliwiajacy realizację zadanego sposobu, zarówno, gromadzenia energii w zasobniku pojemnościowym, jak i jej odbieranie.

\subsection{Fazy pracy}

$\mathrm{Na}$ rysunkach : rys.2., rys.5., rys.6. przedstawiono typowe fazy pracy napędu asynchronicznego bez zasobnika i są to odpowiednio: rozruch i jazda, następnie hamowanie odzyskowe ze zwrotem energii do sieci oraz hamowanie rezystorowe .

W napędzie , w którym zastosowano zasobnik pojemnościowy, występuja dodatkowe stany pracy przedstawione na rys.3 i rys.4. Stanowią je odpowiednio; faza magazynowania energii w zasobniku oraz pobór jej w trakcie rozruchu i jazdy. W realizacji praktycznej, można poprzez odpowiednie zadawanie wysterowania falownika U3, czopera zasobnika U4 oraz szybkiego odłącznika tranzystorowego U1, łączyć ze sobą niektóre fazy, np. fazę zwrotu energii do sieci, magazynowanie energii $\mathrm{w}$ zasobniku tak, aby do maksimum wykorzystać możliwość absorpcji energii prze sieć trakcyjną.

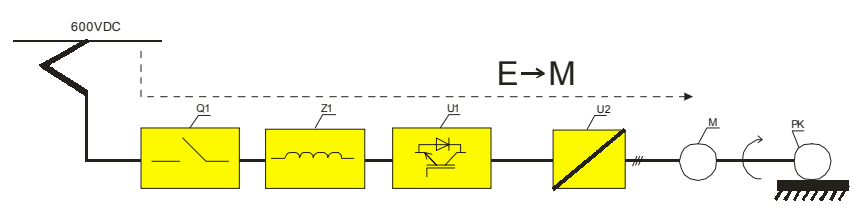

Rys.2: Faza jazdy przy pobieraniu energii z sieci trakcyjnej.

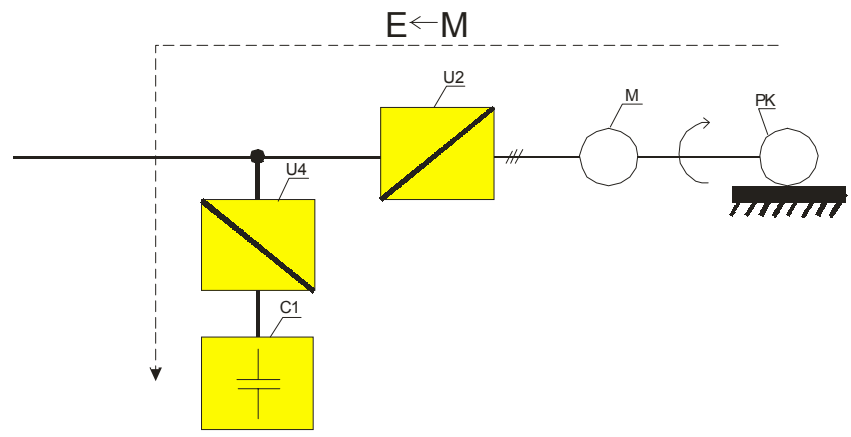

Rys.3: Faza hamowania przy oddawaniu energii kinetycznej do zasobników pojemnościowych.

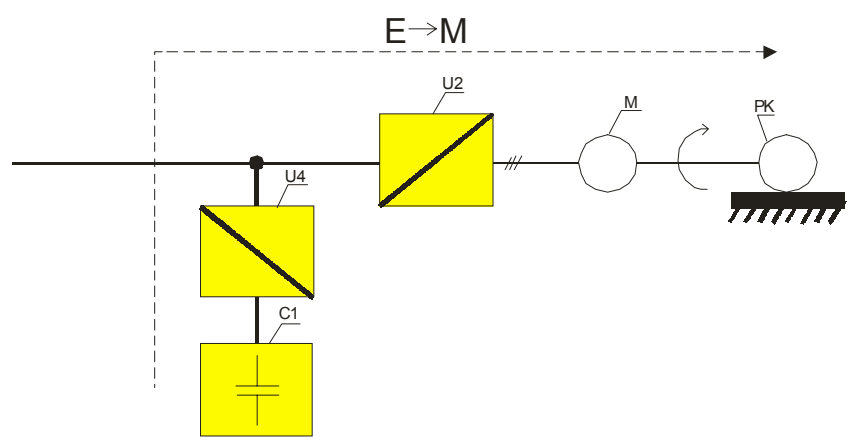

Rys.4: Faza jazdy przy pobieraniu energii tylko z zasobnika kondensatorowego. 


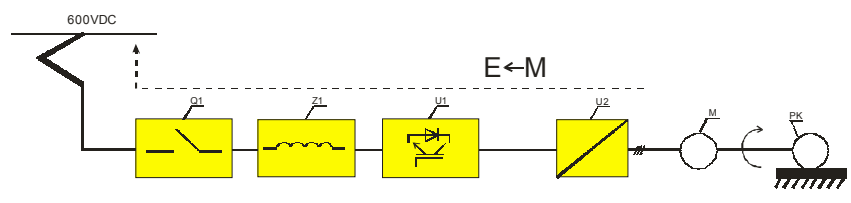

Rys.5: Faza hamowania przy oddawaniu energii do sieci trakcyjnej.

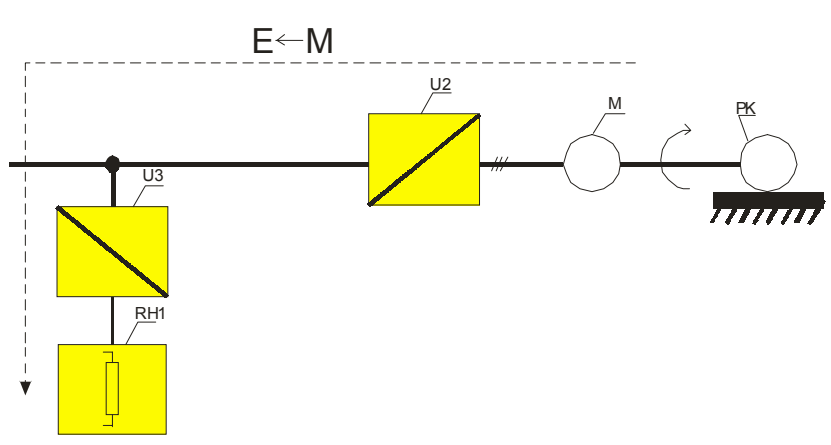

Rys.6: Faza hamowania przy rozpraszaniu energii w rezystorze hamowania.

Jak można zauważyć, z rys. 1. układ napędu jest tak skonstruowany, aby zastosowanie zasobnika było rozwinięciem, które zwiększa parametry techniczne i stanowiło rodzaj opcji umożliwiającej korektę wielkości zasobnika, na skutek zmienności warunków eksploatacji bez konieczności przebudowy już istniejących połączeń.

\section{Wymiarowanie zasobnika pojemnościowego}

W procesie doboru wielkości zasobnika należy uwzględnić szereg parametrów, które wynikają ze stosowania nowej technologii superkondensatorów [5]. Sa to zagadnienia $\mathrm{z}$ jednej strony techniczne i z drugiej strony ekonomiczne, które w tej chwili wydaja się szczególnie ważne . Rozpatrując zagadnienia techniczne można zauważyć, że parametry zasobnika takie, jak pojemność, znamionowe napięcie pracy, nie mają znacznego wpływu na konstrukcję napędu. Jedynej zmianie ulegaja gabaryty i masa samego kontenera zasobnika. Konstrukcja jest powiązana z moca silnik trakcyjnego, która narzuca gabaryty i wymiarowanie podzespołów.

Analizując zagadnienia ekonomiczne należy przynajmniej uwzględnić:

- koszt zakupu zasobnika,

- koszt energii elektrycznej pobieranej z sieci trakcyjnej,

- czas zwrotu kosztów zakupu zasobnika,

- wymagany czas eksploatacji, żywotność zasobnika.

Nie sa znane jednoznaczne metody wymiarowania zasobnika, uwzględniające powyższe zagadnienia ekonomiczne. Stosunkowo wysoka cena zakupu superkondensatorów, wymusza poszukiwanie największych korzyści prze zastosowaniu możliwie taniej, a więc małej baterii zasobnika. Koszt zakupu zasobnika w chwili obecnej pozwala oszacować koszt energii gromadzonej $\mathrm{w}$ superkondensatorach na ok. 0,0036 EUR przy założeniu $1 \times 10^{6}$ pełnych cykli ładowania i rozładowania.

Energia kinetyczna hamującego pojazdu jest to wartość teoretyczna energii, którą można odzyskać i wyraża ją zależność:

$$
E_{K}=\frac{m_{p} \cdot \alpha \cdot V_{p}^{2}}{2}
$$

gdzie: $m_{p}$ - masa pojazdu,

$\alpha$ - współczynnik mas wirujących,

$V_{p}$-prędkość początku hamowania.

Część tej energii pomniejszona o starty wywołane oporami ruchu oraz stratami $\mathrm{w}$ poszczególnych podzespołach, jak pokazano na Rys.1 tj. ;przekładni, silniku, falowniku U2 oraz przekształtniku zasobnika U4 można zgromadzić w zasobniku.

Sprawność przetwarzania energii mechanicznej na elektryczną $(\mathrm{E} \rightarrow \mathrm{M})$ wynosi:

$$
\eta_{p} \cdot \eta_{s} \cdot \eta_{U 2} \cdot \eta_{U 4}=0,96 \cdot 0,94 \cdot 0,98 \cdot 0,96 \approx 0,849
$$

Z zależności (1) wynika, że wielkość zasobnika jest wprost proporcjonalna do masy pojazdu oraz do kwadratu prędkości początku hamowania $V_{p}$. Tak więc szczególnie istotne jest przyjęcie właściwej wartości $V_{p}$. Na podstawie pracy [8] przyjęto $V_{p}=40 \mathrm{~km} / \mathrm{h}$, stąd dla średnio zapełnionego trolejbusu otrzymujemy z (1), przy:

$$
\begin{gathered}
m_{p}=13000 \mathrm{~kg}, \\
\alpha=1,2, \\
V_{p}=40 \mathrm{~km} / \mathrm{h} \quad(11,1 \mathrm{~m} / \mathrm{s}) \\
E_{K}=\frac{1300 \times 1,2 \times 11,1^{2}}{2}=961038 \mathrm{~J},
\end{gathered}
$$

Na podstawie (2) oraz (3) energia , którą może przyjąć zasobnik nie przekroczy wartości:

$$
E_{z a s}=E_{K} \cdot \eta_{E}=815921 \mathrm{~J}=0,227 \mathrm{kWh} \text {, }
$$

Koszt zakupu zasobnika o tej pojemności energetycznej przy obecnych cenach $(\approx 0.013 \mathrm{EUR} / \mathrm{J})$ wynosi:

$$
815921 \cdot 0,013=10607 \text { EUR. }
$$

Jak łatwo można pokazać, zwiększenie prędkości początku hamowania z $V p=40 \mathrm{~km} / \mathrm{h}$ do $V p=50 \mathrm{~km} / \mathrm{h}$ podnosi cenę zasobnika o około $56 \%$.

\subsection{Oszacowanie oszczędności płynących z eksplo- atacji zasobnika pojemnościowego.}


Do obliczeń przyjęto za pracą [7] dane zebrane w poniższej tabeli Tab.1.

Przyjęte parametry ruchowe dla pojazdu komunikacji miejskiej

Tabela 1

\begin{tabular}{|c|c|}
\hline Parametr & Wartość \\
\hline Prędkość początku hamowania & $V_{p}=40 \mathrm{~km} / \mathrm{h}$ \\
\hline $\begin{array}{c}\text { Energia zmagazynowana } \mathrm{W} \\
\text { zasobniku podczas jednego } \\
\text { hamowania }\end{array}$ & $\mathrm{E}=0,227 \mathrm{kWh}$ \\
\hline $\begin{array}{c}\text { Średni przebieg miesięczny } \\
\text { pojazdu }\end{array}$ & $\mathrm{Pm}=5000 \mathrm{~km} / \mathrm{msc}$ \\
\hline $\begin{array}{c}\text { Średnia prędkość komunikacyj- } \\
\text { na }\end{array}$ & $V_{k}=15 \mathrm{~km} / \mathrm{h}$ \\
\hline $\begin{array}{c}\text { Średni miesięczny czas jazdy } \\
\text { mowań }\end{array}$ & $P_{m} / V_{k}=333.3 \mathrm{~h}$ \\
\hline $\begin{array}{c}\text { Srednia miesiezczna liczba ha- } \\
\text { mowan }\end{array}$ & $N_{k}=10000$ \\
\hline Koszt (netto) energii & $0,28 \mathrm{zł} / \mathrm{kWh}$ \\
\hline
\end{tabular}

Zaoszczędzona energia w jednym miesiącu eksploatacji zasobnik wyniesie:

$E_{m s c}=N_{h} \cdot E=10000 \cdot 0,227=2270 \mathrm{kWh}$.

Stąd miesięczna oszczędność wynosi: $K_{m s c}=2270$ $[\mathrm{kWh}] \cdot 0,28[\mathrm{zł} / \mathrm{kWh}]=635,6 \mathrm{zł}$ natomiast $\mathrm{w}$ skali roku:

$E_{r o k}=12 \cdot 2270=27,24 \mathrm{MWh}$ i jest to $7627,20 \mathrm{zl}$.

\subsection{Oszacowanie czasu zwrotu kosztów zasobnika}

Z wcześniej dokonanych obliczeń, gdzie koszt zakupu samego zasobnika wynosi ok. 10607 EUR, co przy kursie 4,50 stanowi 47 731,5 zł oraz wartości zaoszczędzonej energii w ciagu roku 7627,2 zł pozwala na zwrot jego zakupu w czasie: $T_{z w r}=\frac{4773,15}{7627,2}=6,26$ roku.

Jest to wartość przybliżona nie uwzględniająca kosztów obsługi oraz przekształtnika sterującego pracą zasobnika.

\subsection{Oszacowanie czasu eksploatacji zasobnika}

Dane techniczne udostępniane przez producentów superkondensatorów zapewniają, że są one przewidziane do przeprowadzenia minimum $10^{6}$ pełnych cykli, ładowanie- rozładowanie. Przy założeniu, iż miesięcznie wystapi 10000 cykli uzyskujemy: $T_{e k s p}=10^{6} / 10^{5}=100$ miesięcy $\rightarrow 8$ lat i 4msc, po którym powinna nastapić wymiana superkondensatorów.

\section{Praktyczna realizacja napędu dla trolejbusu}

W trakcie projektu, opierając się na wybranej strukturze układu, przeprowadzono analizę techniczną oraz obliczenia i symulacje numeryczne. Szczególny nacisk został położony na rozpoznanie nowej technologii kondensatorów o dużej pojemności superkondensatorów, gdzie muszą być zapewnione właściwe warunki ich pracy, aby uzyskać wymaganą żywotność.

Poniżej przedstawiono schemat ideowy napędu oraz rysunki konstrukcyjne najważniejszych podzespołów.

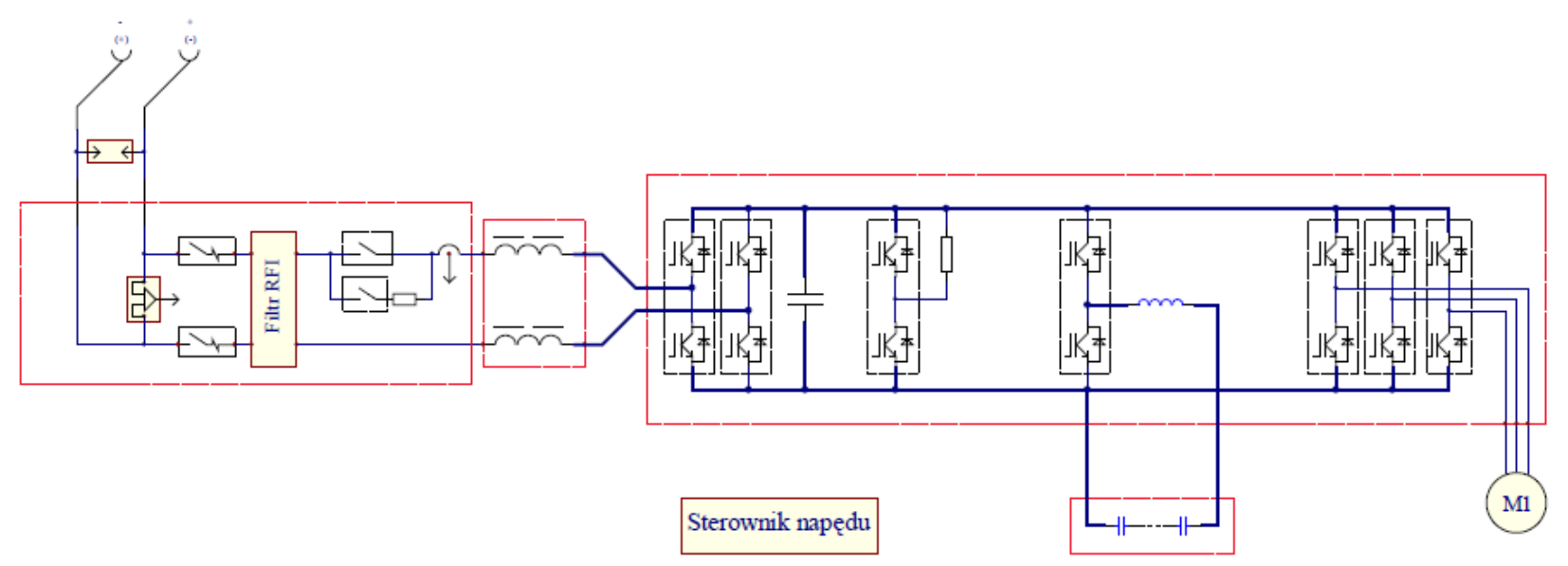

Rys.7: Schemat obwodu głównego napędu trolejbusu z zasobnikiem suprekondensatorowym.

Pozycja 1 - Dławik wejściowy filtru,

Pozycja 2 - Prostownik sterowany,

Pozycja 3 - Czoper hamowania wraz z rezystorem hamowania,

Pozycja 4 - Przekształtnik dwukwadrantowy zasobnika pojemnościowego,

Pozycja 5 - Falownik trakcyjny,

Pozycja 6 - Silnik trakcyjny,

Pozycja 7 - Zasobnik superkondensatorowy,

Pozycja 8 - Sterownik napędu,

Pozycja 9 - Stycznikowa aparatura łączeniowa. 


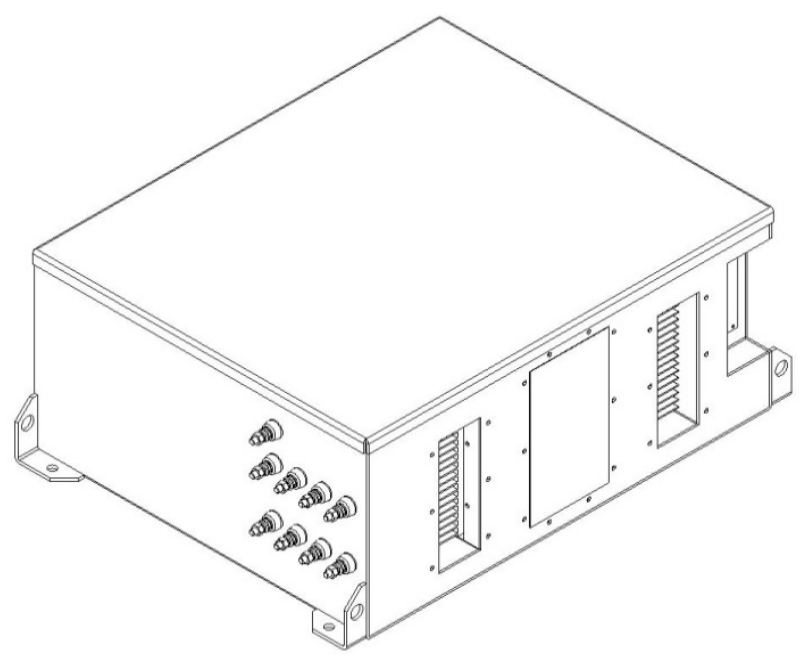

Rys.8: Falownik napędu.

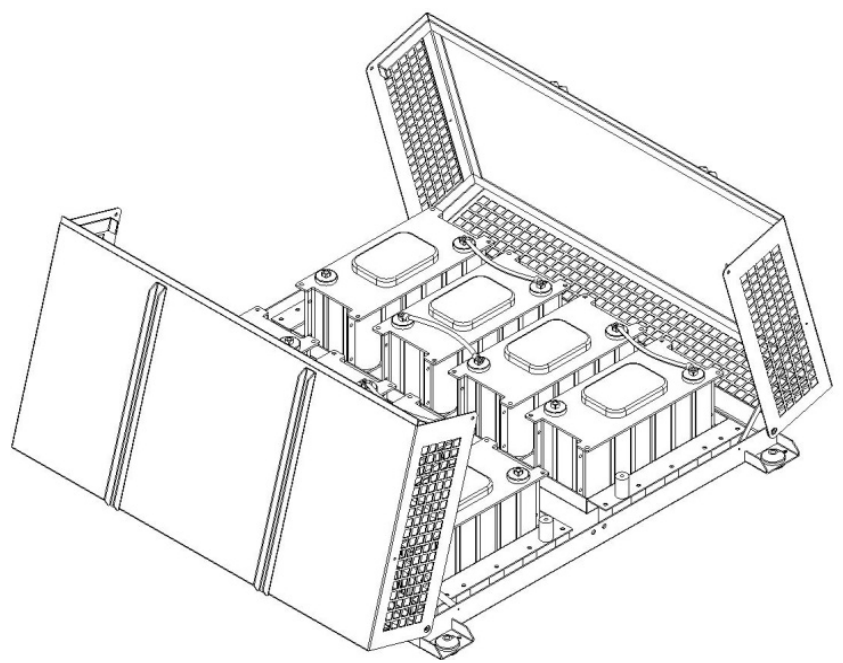

Rys.9: Zasobnik superkondensatorowy (pokrywy otwarte).

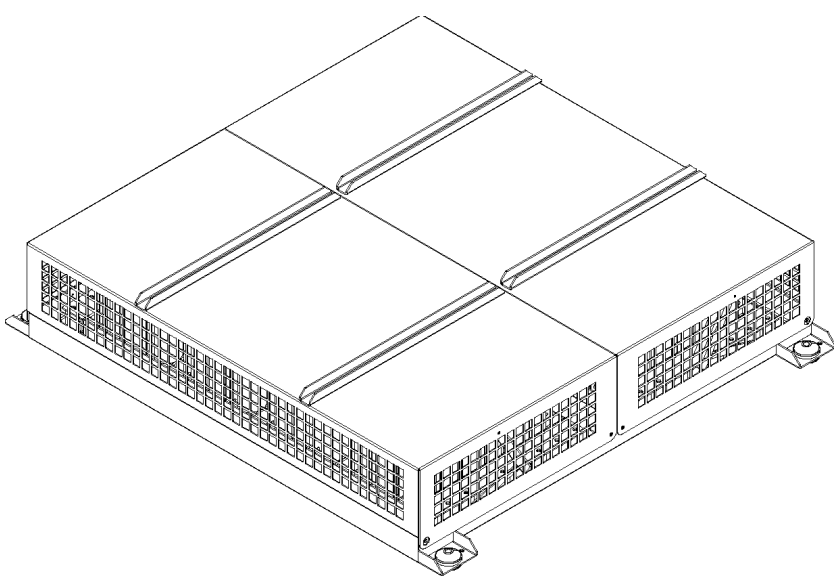

Rys.10: Zasobnik superkondensatorowy (pokrywy zamknięte).

Urządzenia zostały przewidziane do zabudowy w modernizowanych pojazdach na bazie konstrukcji czeskiego trolejbusu T 14. Aparatura stykowa, filtr wejściowy, falownik, przekształtnik zasobnika oraz sterowanie umieszczono w dostępnych wnękach pod podwoziem. Rezystor hamowania oraz zasobnik pojemnościowy są zabudowane na dachu.

Pojazd jest wyposażony w pomiar i rejestrację zużytej energii.

\section{Podsumowanie}

1. W wyniku przeprowadzonych prac projektowych z uwzględnieniem analizy dostępnej literatury, została opracowana struktura układu napędowego oraz określona wielkość zasobnika pojemnościowego dla modernizowanego trolejbusu.

2. Zabudowa zasobnika na pojeździe, ułatwia efektywne sterowanie pracą baterii superkondensatorów, obniża straty w sieci trakcyjnej oraz umożliwia samodzielne poruszanie się ( zjazd awaryjny) pojazdu przy braku napięcia w sieci trakcyjnej [1], [6].

3. Zastosowanie zasobnika $\mathrm{w}$ układzie $\mathrm{z}$ napędem asynchronicznym, zwiększa oszczędność energii w stosunku do napędu z możliwością hamowania odzyskowego (o $10 \div 15 \%$ ), zwłaszcza w ruchu poza godzinami szczytu [7].

4. Wielkość zainstalowanego zasobnika zależna jest od masy pojazdu i wymagań ruchowych. Znaczące efekty energetyczne uzyskuje się dla zasobnika o wielkościach $\geq 0,14 \mathrm{kWh} / 10$ ton [7].

5. Przy obecnych cenach energii oraz zakupu baterii superkondensatorów, szacowany czas zwrotu kosztów zasobnika, to minimum 6,26 roku. Natomiast czas eksploatacji to minimum 8,33 roku.

\section{Literatura}

[1] Giziński P., Giziński Z.: Kondensatorowy zasobnik energii dla pojazdów trakcji elektrycznej. Konferancja Naukowa Trakcji Elektrycznej. Semtrak 2006, Zakopane,

[2] Diego Iannuzzi: Improvement of the Energy Recovery of Traction Electrical Drives using Supercapacitors. 2008 13th International Power Electronics and Motion Control Conference (EPE-PEMC 2008),

[3] R. Barrero, X. Tackoen, J. Van Mierlo: Analysis and configuration of supercapacitor based energy storage system on-board light rail vehicles. 2008 13th International Power Electronics and Motion Control Conference (EPE-PEMC 2008),

[4] Sejin Noh, Jaeho Choi, Hyung-Cheol Kim, Eun-Kyu Lee.: PSiM Based Electric Modeling of Supercapacitors for Line Voltage Regulation of Electric Train System. 2nd IEEE International Conference on Power and Energy (PECon 08), December 1-3, 2008, Johor Baharu, Malaysia PSiM,

[5] L. Latkovskis, V. Bražis: Simulation of the Regenerative Energy Storage with Supercapacitors in TatraT3A Type Trams. Tenth International Conference on Computer Modeling and Simulation,

[6] Ricardo Barrero*, Xavier Tackoen**, Joeri Van Mierlo*:Improving energy efficiency in public transport:stationary supercapacitor based energy storage systems for a metro Network. IEEE Vehicle Power and Propulsion Conference (VPPC), September 3-5, 2008, Harbin, China,

[7] Dariusz Stanistawczyk: Badanie celowości i możliwości zastosowania kondensatorowych zasobników energii w trakcji miejskiej. Praca Dyplomowa Magisterska. Politechnika Łódzka, Łódźczerwiec 2009. 